\title{
Global governance and inter-organizational relationships in the nuclear safety sector
}

\author{
Kjerstin L. Kjøndal ${ }^{1}$ (1)
}

Received: 14 July 2021 / Accepted: 27 October 2021 / Published online: 25 November 2021

(C) The Author(s) 2021

\begin{abstract}
In response to global challenges the interconnectedness between different organizations is seen as the sine qua non, and one of the most important aspects of the organizational environment is cooperation and conflicts between organizations. This paper aims at contributing to an emerging 'inter-organizational turn' in world politics by studying the relationship between the United Nations Scientific Committee on the Effects of Atomic Radiation (UNSCEAR), the International Commission on Radiological Protection (ICRP), and the International Atomic Energy Agency (IAEA), and the paper suggests that inter-organizational cooperation and conflict are based on flows of information, trust, resource dependencies, and how responsibilities and roles are divided between organizations. Moreover, the paper indicates that organization type and organization size are important to understand patterns of cooperation and conflicts between organizations operating at the global level, and the paper also suggests that organizational birthmarks are important to understand why tensions are triggered.
\end{abstract}

Keywords Global governance · International organizations (IOs) · Interorganizational relationships $\cdot$ Nuclear safety $\cdot$ Oganizational history $\cdot$ Organizational structures

\section{Introduction}

"What makes the world hang together?" John Ruggie famously asked and contributed to the pursuit of understanding how the world is governed, ordered, and organized (Barnett \& Finnemore, 2004: 10; Ruggie, 1998: 1; Weiss \& Wilkinson, 2018: 11). In response to global challenges, the interconnectedness between different actors is seen as the sine qua non and scholars are, therefore, encouraged

Kjerstin L. Kjøndal

kjerstin.kjondal@uia.no

1 Department of Political Science and Management, Universitetet i Agder, P.O Box 422, 4604 Kristiansand, Norway 
to focus on relationships between global organizations (Biermann \& Koops, 2017: 2, 5 and 13; Finnemore, 2014; Legrand, 2019; Lipson, 2017: 67; Stone \& Ladi, 2015; Weiss \& Wilkinson, 2018: 13). Studies suggest that one of the most important aspects of the organizational environment is cooperation and conflicts between organizations, and scholars must thus examine how and why organizations may both clash and cooperate (Biermann \& Koops, 2017: 19; Karns et al., 2015: 67; Schneiker, 2017: 321). Arguably, cooperation between key global organizations is essential to promote common understandings and policy harmonization across the globe, while conflicts may lead to policy fragmentation and a lack of common understandings with important consequences for practises at the regional and national level. This paper aims at contributing to an emerging 'inter-organizational turn' in world politics (Biermann \& Koops, 2017: 1) where organizations and the relationships between them are treated as more than mere instruments of states (Franke, 2017). Consequently, organizational characteristics are important, and the paper shows how organization type, organization size, and organizational birthmarks affect relationships between organizations at the global level.

The paper asks: What shapes cooperation and conflict between organizations at the global level, and why do conflicts arise between organizations with a longstanding history of cooperation? The paper studies the United Nations Scientific Committee on the Effects of Atomic Radiation (UNSCEAR), the International Commission on Radiological Protection (ICRP), and the International Atomic Energy Agency (IAEA), and these are the most influential global actors dealing with safety issues in 'the nuclear safety sector'. The nuclear safety sector is divided into three different pillars: safety, safeguards, and security. Safety is defined as the protection of people, environment, and society from the consequences of radiation, and it includes radiation protection, emergency preparedness, and nuclear safety, which in general is about how to operate nuclear facilities to avoid accidents. Safeguards refer to ensuring that nuclear material, technology, and information are used for peaceful purposes, and it thus includes arms control and non-proliferation. Finally, security is linked to both safety and safeguards, and it is mainly about protecting nuclear facilities from terrorism, and how to avoid theft of nuclear material, technology, and information.

The three organizations included in this study vary according to the independent variables of organization type, size, and birthmarks, and they are essential to create safety recommendations and standards with vast consequences for safety practices, rules, and laws at the regional and national level. Moreover, these organizations, and the relationship between them, provide an opportunity to study why tension arises between organizations with a longstanding history of cooperation, and by choosing actors within one sector, it enables some degree of controlling for noise stemming from other policy sectors. In short, the UNSCEAR is a scientific committee in the United Nations (UN) system, and its main objective is to assess and report levels and effects of radiation. The members of the UNSCEAR are states, however, these states are not represented by politicians, but rather by national experts. Moreover, the UNSCEAR has a small separate secretariat, and hence, the UNSCEAR possesses traits of both inter-governmental organizations (IGOs) and expert bodies. The 
ICRP is a non-governmental organization (NGO) and an expert body providing recommendations and guidance on all aspects of radiation protection. The IAEA is an IGO with a broad portfolio. However, a core task is to develop and publish global safety standards.

This article suggests that inter-organizational cooperation at the global level is based on continuous flows of information, high trust, resource dependencies and a clear separation of tasks and responsibilities within a shared issue area (see Table 1), and to account for variation in patterns of cooperation and conflict, the paper studies the impact of organization type, size, and birthmarks on inter-organizational relationships. In so doing, the paper highlights two basic assumptions. First, organizations matter, and this research underscore the role of organizational variables to understand inter-organizational relationships at the global level (Olsen, 2018a). Second, history and context matter, and scholars have emphasized the essential role of history and the problems of universal, non-contextual explanations (Lægreid, 2020: 424; Olsen, 2018a). As different organizations are located differently in time and space, the question is how the past affects the future and how organizations learnor not-from experience and changing environments (Olsen, 2018a). Moreover, scholars argue that there is a need to study the links between the historical development of cooperation and conflicts, as well as organizational forms and processes (Olsen, 2018a).

The paper contributes to three main literatures. First, the paper contributes to bridge the gap between studies of international organizations (IOs) and organization theory. Traditionally the relationship between these two strands of literatures have been marked by mutual neglect (Jönsson, 2017: 50). However, it has been argued that organization theory is a powerful instrument for approaching governance as organizational factors are expected to create biases in governance processes, making some choices more likely than others (Egeberg \& Trondal, 2018: 1-4; Lægreid, 2020: 422). This paper shows how variables like organization size affect relationships between organizations. Second, the paper speaks to the literature on international public administration (IPA) by highlighting the vital role of international bureaucracies in global governance. In so doing, the paper does not expect IOs to act as coherent wholes, and studies suggest that non-elected bureaucrats may use their central position, privileged access to information, technical expertise, and professional authority to influence global governance (Bauer \& Ege, 2016). This paper shows how international secretariats are important for information sharing and trust between organizations, and thus they influence degrees of cooperation and conflict

Table 1 Conceptualization of cooperation and conflicts in inter-organizational relationships

\begin{tabular}{ll}
\hline Cooperation & Conflicts \\
\hline Continuous flows of information & No flow of information \\
High trust & Low trust \\
Distinct resources other organizations need & Overlap of resources \\
Clear separation of tasks and responsibilities & Duplication of tasks \\
& and responsibilities \\
\hline
\end{tabular}


between organizations. Third, cooperation between IGOs and NGOs is not very well explained (Steffek, 2013) and achieving policy coherence and synergies between IGOs and NGOs have been identified as one of the core challenges of global governance (Biermann \& Koops, 2017: 2). Moreover, IGOs may be defined as 'metaorganizations' (Ahrne \& Brunsson, 2005), while NGOs like the ICRP, are not. This paper thus indicates that differences between IGOs and NGOs related to the members of the organizations, contribute to our understanding of what shapes relationships between IGOs and NGOs.

The article proceeds as follows. Section two presents the theoretical framework in two steps: First, cooperation and conflicts are conceptualized. Second, the independent variables are presented including propositions and expectations. Next, section three introduces the method and data, while section four present the empirical findings. Finally, section five summarizes key findings and suggest contributions to the literature.

\section{Theoretical framework}

There is a growing interest in studying cooperation among international organizations (IOs) (Biermann \& Koops, 2017: 1-2). However, scholars propose that cooperation is always accompanied by the potential for conflicts and the default condition between organizations is not necessarily harmony (Biermann \& Koops, 2017: 20). To conceptualize both cooperation and conflicts between organizations, this paper draws on inter-organizational relations (IOR) literatures. The study of IOR is focused on understanding different aspects of inter-organizational relationships like their origins, patterns, and consequences (Cropper et al., 2008: 4), and inter-organizational theorists, study how and why organizations both cooperate and compete (Karns et al., 2015: 68).

In this paper, cooperation is conceptually unpacked by four different proxies. First, cooperation is recognized by continuous flows of information and the interaction between organizations is thus focused on information sharing to ensure cooperation and to avoid misunderstandings and tensions. The sharing of information may then reflect a common interest among organizations, and information-sharing behaviour is employed as an approach to strengthen relationships between information givers and receivers (Yang \& Maxwell, 2011). Secondly, scholars argue that successful organizational relations over longer periods of time, is recognized by high degrees of trust, and trust is a response to the problem of complexity and uncertainty in social interactions (Bachmann et al., 2001; Brugger et al., 2017: 407; Costa et al., 2018; Fulmer \& Gelfand, 2012; Paliszkiewicz, 2011). Moreover, the trust may be grounded in an assessment of an actors' motivation and/or competence (Brugger et al., 2017: 409), and the argument is that high trust is an essential part of wellfunctioning cooperation, while low trust is a core feature of conflicts.

Third, resource dependency theories suggest that resource exchange is the core activity in inter-organizational relations (Biermann \& Koops, 2017: 9; Hillman et al., 2009), and that organizations are drawn into inter-organizational relationships because they need resources (Van de Ven, 1976). Hence, organizations will 
cooperate in cooperation to achieve goals and harvest mutual benefits (Laimer, 2015; Oliver, 1990). Organizations are especially affected by the scarcity of resources such as personnel, finances, information, knowledge, and expertise (Karns et al., 2015: 68; Schneiker, 2017: 325-326). However, organizations need more than these resources if they are to survive (Scott, 2008: 59). Hence, another type of resource organizations' need, is authority. Authority on the global level can be divided into two basic types, namely political authority and epistemic authority (Zürn, 2017). Political authority rests on the acknowledgment that the world need institutions that are authorized to make collectively binding decisions to promote the common good and to prevent chaos, while epistemic authority is based on expert knowledge and moral integrity, and the perspectives and views of an authority are adopted because the actor appear to be both well-informed and nonpartisan at the same time (Zürn, 2017). Finally, cooperation is linked to tasks and responsibilities. If organizations, operating within the same issue-area, have distinct tasks and responsibilities, they are more likely to achieve their goals. The output of one organization might thus be important input for another organizations (Alexander, 1995: 31), and interdependent processes might emerge through the division of tasks and functions between organizations (Van de Ven, 1976). Consequently, actors might agree upon a division of labour to avoid conflicts and costs related to duplication of tasks and responsibilities (Biermann \& Harsch, 2017: 139).

This paper suggests that cooperation and conflicts in inter-organizational relationships are at the opposite ends of a continuum, and conflicts are thus recognized through a lack of cooperation: No flow of information, low trust, overlap of resources, and duplication of tasks and responsibilities. No flow of information may imply a passive position or a position of active information protection. Low degrees of trust implies questioning an actors' motivation and/or competence, and it may hamper cooperation and trigger conflicts. Organizations may also compete over resources, and thus attempt to increase their relative position in the field by showing differences in strength (Reinalda \& Kille, 2017: 217). Finally, duplication of tasks and responsibilities may lead to domain conflicts. Domain conflicts are a consequence of organizations encroaching the domain of others, often via duplication of output, mandates, or tasks, stimulating domain-protective measures, turf battles or conflicts by affecting the relevance of the other organization (Biermann \& Harsch, 2017: 139; Biermann \& Koops, 2017: 7). On this basis, tensions arise in inter-organizational relationships due to decreasing degrees of cooperation, and tensions may lead to conflicts.

To account for variation, this article studies the impact of organization type, size, and birthmarks on patterns of cooperation and conflict. These variables reflect variation between the three organizations under study and they are derived from the empirical findings. In the following sections, the independent variables are presented.

First, organization type may influence relationships between organizations, and this paper focus on relationships between IGOs, NGOs, and expert bodies. The main differentiating feature between IGOs and NGOs is that the members of an IGO are states, while members of NGOs are individuals (or associations) (Charnovitz, 2011). IGOs may thus be characterized as 'meta-organizations' where the members of the 
organizations are other organizations and states (Ahrne \& Brunsson, 2005; Jönsson, 2017: 62). Consequently, IGOs rely to a great degree on their member states, while NGOs are independent of governments, and they rely on their individual members and donors. The core components of expert bodies are specialized knowledge coupled to organizational autonomy. These bodies thus operate at arms' length from governmental control, at a minimum, and at the same time the workforce is characterized by highly educated and skilled experts (Krick \& Holst, 2020: 1-2). Expert bodies are also targeted toward the expectations of well-informed experts in their field, and they must perform to retain the approval of its expert observers (Boswell, 2017: 31). These differences create some expectations regarding how these types of organizations may relate to each other. First, member state concerns about organizational autonomy will typically prevent IGOs from engaging in close forms of interorganizational cooperation (Biermann \& Harsch, 2017: 146), and studies show that NGOs access within and across international organizations, is highly constrained by state concerns with national sovereignty (Tallberg et al., 2013: 3). NGOs on the other hand, have more freedom of action and will seek cooperation toward relevant decision makers and policy forums (Schneiker, 2017: 320 and 326). NGOs may thus have strong incentives to cooperate with IGOs and other NGOs, and NGOs rarely work alone for very long (Karns et al., 2015: 244). Second, meta-organizations such as IGOs, are more autonomous and they have access to more resources such as finances, expertise, personnel, and information, compared to organizations with individuals as members because organizations concentrate resources (Ahrne \& Brunsson, 2005; Jönsson, 2017: 62). Member states also supply political support and thus potentially fuel IGOs with political authority. NGOs and expert bodies, on the other hand, may hold epistemic authority, but they must take responsibility themselves for ensuring the resources needed. Hence, IGOs are less vulnerable considering resources compared to NGOs, and IGOs will also inherently hold resources other organizations need and desire. Third, organizational specialization has important implications for inter-organizational cooperation, and functional overlap increase the potential for domain conflicts (Biermann \& Harsch, 2017: 139). In sum this leads to three propositions:

P1: IGOs will be less involved in information-sharing compared to NGOs, and the ICRP will have less access to important forums in the IAEA, compared to the IGOs access to the ICRP. The expectancy is thus that ICRP will take more initiatives toward giving access to and sharing information with the UNSCEAR and the IAEA, than the other way around.

P2: IGOs are less dependent on resources NGOs hold, compared to NGOs dependence on IGOs resources. The UNSCEAR is not a typical IGO, and the expectation is thus that the IAEA, in particular, is less involved in conflicts and competition over resources compared to the ICRP.

P3: The same type of specialized organization, like expert bodies, operating within the same issue-area, are more likely to duplicate each other's tasks and responsibilities. The expectancy is thus that domain conflicts will develop more easily between the UNSCEAR and the ICRP, compared to conflicts toward the IAEA. 
Furthermore, the size of an organization, measured in staff size and budgetary size, supply capacity for organizations to act (Egeberg \& Trondal, 2018: 7). Consequently, large organizations are less dependent on other actors to carry out their tasks, and they are more autonomous than smaller organizations. Organizations that do not dispose of many resources in terms of staff and money may thus seek to work together with organizations that are better equipped to achieve their goals (Schneiker, 2017: 326). Two propositions follow:

P4: Small organizations, like the UNSCEAR and the ICRP, will more actively seek cooperation toward big organizations, like the IAEA, compared to big organizations seeking cooperation toward small organizations.

P5: Big organizations have more capacity to interact with other organizations, and the expectancy is that flows of information will be easier to uphold in the relationship involving the IAEA, compared to flows of information between the UNSCEAR and the ICRP.

Finally, all organizations have their birthmarks, and they are thus marked by the time in history at which they arrive and the ideas and resources available at that time (Olsen, 2018b). Moreover, organization characteristics at the time of their founding tend to remain and be carried into the future (Gornitzka \& Sverdrup, 2011). Consequently, the basic structure of the organization will remain relatively stable (Stinchcombe, 1965: 153), and through institutionalization, organizations create coordination mechanisms and communication channels which persist (Marquis \& Tilcsik, 2013; Scott, 2008: 124). Arguably, based on individual organizational birthmarks, relationships between organizations also have their own birthmarks. Combined, these birthmarks are key to understanding cooperation and conflicts in inter-organizational relationships. One proposition follows:

P6: Organizations carry the marks of their initial ideas and resources, and it will impact cooperation and conflicts between organizations. The expectancy is thus that patterns of cooperation and conflicts between organizations observed today, will correspond to the ideas and resources available at both the establishments of the organizations and at the establishments of the relationships between them.

\section{Method and data}

To unpack the relationship between the UNSCEAR, the ICRP, and the IAEA this study benefits from an original dataset based on a qualitative research method. Qualitative methods encompass rich and detailed data which may provide deep understanding. Moreover, interviews open a window into the perceptions of interviewees, their experiences, and underlying processes, enabling a better understanding of complex social realities (Buchana et al., 2018; Smith \& Elger, 2014: 119). The empirical findings of this paper are based on interviews with experts, supplemented by documents. These experts represent an elite, and scholars discuss the difficulties with studying elites in general, by emphasising obstacles such as gated communities and 
power imbalances (Mikecz, 2012; Petintseva et al., 2019). When adding the complexity of distance, where elites are situated across the globe, data gathering poses a real challenge. To overcome such obstacles, studies suggest that qualitative research methods may be the best alternative to gain access to data (Harrington, 2017: 39).

The interview data consists of three datasets. The first set comprises 37 semistructured expert interviews with officials from the national authorities on radiation protection and nuclear safety in the five Nordic countries, conducted in 2018 and 2019. All interviewees are highly educated and skilled professionals, and all have experience from working at the international level. However, some of the interviewees from the Nordic level have extensive international experience, including being members of the ICRP, leading expert groups related to the UNSCEAR, and representing their country in important committees in the IAEA. These 37 interviews were, therefore, essential to understand the overall global governance structures in the nuclear safety sector, and also to understand the inner workings of all three organizations. The second dataset consists of ten interviews conducted during the fall of 2020. These interviewees include both experts and staff related to the UNSCEAR, the ICRP and the IAEA, and they were also selected based on their central position and experience. Thirdly, five interviews were conducted during the spring of 2021. These interviews did not include new interviewees, but the interviews provided deepened understanding on 'the radon situation', the secretariats of the organizations, as well as cooperation and tensions between the organizations. In sum, the dataset thus consists of 52 interviews, but only 47 individual interviewees.

All the interviews targeted aspects such as contact patterns, perceptions of tasks and roles, and experiences with the relationships between the organizations under study. Moreover, all 52 interviews are important for the findings presented. However, the second and third datasets serves as primary data, combined with the interviews with Nordic experts with specific experience from the global level. The study also benefited from publicly available information from the three organizations' homepages, with a special emphasize on historical documents. Moreover, Bo Lindell's book series on the history of radiation, radioactivity, and radiological protection has been important, and also other published articles on the history of the three organizations.

The data is mainly presented at an aggregated level. Most interviews were conducted face-to-face, except 20 interviews conducted via Skype, Lifesize, and Zoom. All interviews were taped and transcribed and both historical documents and the transcribed interviews, were uploaded to the qualitative data analysis software NVivo. NVivo was especially important in structuring and systematizing the vast amount of data, which was essential in order to analyze the data properly. To preserve their anonymity, each interviewee was assigned an interview code: numbers for Nordic level interviewees and letters for international level interviewees. Drafts of the paper were also sent to all quoted interviewees, and they were invited to offer comments before publishing. Finally, the data were collected in accordance with the requirements of the Norwegian Centre for Research Data. 


\section{Empirical findings and discussion}

The empirical findings are presented in two main parts. First, the relationships between the UNSCEAR, the ICRP and the IAEA are assessed according to the conceptualization of cooperation and conflicts. In sum, the data suggests that there are two main relationships between the three organizations: the relationship involving the IAEA, and the relationship between only the UNSCEAR and the ICRP. The relationship involving the IAEA is marked by cooperation, while the relationship between the UNSCEAR and the ICRP carries tensions. The data also suggest that these tensions have become more apparent in recent years, compared to earlier stages in the UNSCEAR-ICRP relationship, and in this paper these tensions will be exemplified by the 'radon situation'. In short, the radon situation stems from the publication of different dose conversion factors from the UNSCEAR and the ICRP, and the main aim is thus to use the radon situation to illustrate the tensions between the UNSCEAR and the ICRP. The situation is described as follows:

I think the radon situation definitely caused quite a lot of contention at different levels, and quite a lot of contention internationally, because people are like "UNSCEAR represent the science and we should use their dose conversion factor", but other people said "but ICRP makes recommendations for radiation protection, so we should use their dose conversion factor". And then the IAEA was stuck between a rock and a hard place because which one should they choose? (Interviewee G)

Secondly, variations in the empirical findings are discussed regarding the independent variables of organization type, size, and birthmarks. The data show that all variables contribute to explaining inter-organizational relationships on the continuum between cooperation and conflict. Organization type and size are central to understanding flows of information, resource distinctiveness and resource dependencies, as well as domain conflicts. Organizational birthmarks, on the other hand, seem to provide a deeper understanding of what may spark tensions between organizations with a longstanding history of cooperation.

In the following sections, the two different relationships will be discussed according to the conceptual model describing cooperation and conflicts. Hence, the discussion will be based on how information flows between the organizations, degrees of trust, the distribution and distinctiveness of resources, and the division of tasks and responsibilities. Both traits related to cooperation and conflicts will be discussed simultaneously.

\section{Flow of information}

First, regarding flows of information, the relationship involving the IAEA seem to enjoy more continuous flows of information, compared to the relationship between the UNSCEAR and the ICRP. Information sharing is apparent both through formalized structures and through informal channels. Formal flows of information materialize in both direct communication between the secretariats, and also through mutual 
representation. The data imply that information sharing through direct communication is much more extensive between the IAEA and the two other organizations, compared to information sharing between the UNSCEAR and the ICRP. Interviewees related to staff-functions, describe that communication toward the IAEA may happen daily basis, including both informal and formal interactions, while communication and information sharing between the UNSCEAR and the ICRP secretariats is generally limited to approximately once every month or less. However, mutual representation through formalized structures seems to be important, and the data indicate that all the organizations enjoy formal relationships to facilitate information sharing. The UNSCEAR and the ICRP are observers to the Commission on Safety Standards (CSS), which is the highest-ranking IAEA committee related to the development of the global safety standards, as well as other relevant IAEA committees. Moreover, the ICRP and the IAEA are observers to the UNSCEAR. The UNSCEAR and the IAEA have formal relations with the ICRP, demonstrated by invitations to participate in strategic discussions and ICRP committee meetings. The ICRP thus emphasizes active participation, contrary to the passive observer. It has also been established an inter-agency committee on radiation safety (the IACRS) where both the UNSCEAR and the IAEA are members, while the ICRP is an observer. However, the data does not indicate that this is an important arena for information sharing between the UNSCEAR, the ICRP, and the IAEA.

Furthermore, flows of information may also be directed through informal channels, and this is especially apparent between individuals who have, or have had, multiple affiliations across the organizations:

You can have members of the ICRP main commission who are also national delegates to UNSCEAR. So, the information flows both ways and I do not see the overlap as a problem. The overlap ensures that there is continuity, that there is a good flow of information. (Interviewee 5)

And:

At one time the chairman of the committee one [of the ICRP] was also the head of the UK delegation to UNSCEAR. I don't think we ever formally recognized that he could represent us. But there was always a feeling of, well, at least we would know what was going on. We would know if there were problems arising and these problems would then be drawn to our attention. (Interviewee $\mathrm{H}$ )

The data suggest that this kind of informal information sharing has been highly important, especially between the UNSCEAR and the ICRP. However, the data indicate that there has been a gradual change in recent years, in which there is less informal information sharing between the UNSCEAR and the ICRP now, compared to earlier. The radon situation illustrates the situation well. Interviewees from the ICRP describe that there were hundreds of interactions, mostly informal, between the ICRP and the IAEA where they informed each other on the work they were doing related to the radon situation. On the other hand, interviewees report few attempts of information sharing between the UNSCEAR and the ICRP: 
There is full agreement on the science related to measurements of radon concentrations. But to get from the concentration to the potential of harm, you need to do some modelling and you can do modelling in different ways. I think it's a bit difficult to understand why, in the very beginning when these models were being developed, there was not a closer cooperation between ICRP and UNSCEAR, but it may have to do with the people that were involved. (Interviewee 5)

\section{Trust}

Regarding levels of trust, the data indicate that no one questions the competence of the three organizations. The UNSCEAR, the ICRP, and IAEA committees like the safety standards committees and the CSS, are perceived to be highly competent and comprising the best scientists in the world. However, trust in motivations is more nuanced between the organizations, and it is especially evident in the relationships between the UNSCEAR and the ICRP. Moreover, trust in motivations is linked to individuals, and how individuals, with different agendas, may influence the workings of the organizations:

I think UNSCEAR produces very good reports, but that's largely regardless of the UNSCEAR meetings. The committee meetings tend to be, I would say, potentially dominated by particular individuals. ... And you know, sometimes you will hear people saying, "Well, UNSCEAR have said such and such". And you say, "Well, actually, that's you". (Interviewee I)

And in relation to the radon situation one interviewee describe the situation as follows:

And then they [ICRP] came up with a number that was higher than the UNSCEAR-a higher risk! I'm sure if the previous people who had been involved in the lower number were still on ICRP, it wouldn't have been that high, because my understanding was frankly, that it was political and it was linked to uranium mining. (Interviewee $\mathrm{H}$ )

The role and influence of the ICRP, as an NGO, is also questioned:

During the drafting and revision of the IAEA safety standards, the question of the influence of the ICRP has been raised and questioned. So, not everyone at the agency [IAEA] or at the national level is a friend of the ICRP, and some people find it problematic, this marriage to ICRP. ... And the question has been raised several times: How is it possible that an NGO, has this enormous influence? Is it acceptable? (Interviewee 5)

IGOs, like the UNSCEAR and the IAEA, are also questioned related to member state interests. This is for instance observed in the work of the CSS:

The job is to make sure that the safety is maintained regardless of the technology. ... However, certain members of the CSS will come to the CSS with 
instructions from their capitals to respond to the safety standard. ... So, there will always be a small protective element, or a territorial element, trying to influence the safety standards, and defence of the technology will take place. (Interviewee F)

However, such dynamics do not seem to influence the relationship between the UNSCEAR, the ICRP, and the IAEA. In fact, the data suggest that it is easier to question the motivation of the UNSCEAR and the ICRP, compared to the IAEA, even though some of the same concerns are present in the IAEA. Moreover, the ICRP is also questioned for being an NGO, and the data thus indicate that it is especially important for the ICRP to appear as trustworthy in order to build relationships with other organizations, as compared to the IAEA where trust might be less important.

\section{Resources}

The overall picture is that the UNSCEAR and the ICRP are more dependent on resources the IAEA hold, especially the political authority of the IAEA, compared to resources the UNSCEAR and the ICRP may offer each other. The UNSCEAR and the ICRP are thus more vulnerable regarding resources, compared to the IAEA. Moreover, all the organizations have some overlap regarding resources such as expertise, knowledge, information, and epistemic authority, while they differ on finances, staff, and political authority. The UNSCEAR and the ICRP have small budgets and secretariats, but both organizations, and the ICRP in particular, have high degrees of epistemic authority. The IAEA has big budgets, a large staff, and political authority. On a more detailed level, considering resources such as finances and personnel, the data shows substantial differences between the organizations. The IAEA is a large organization with a big budget and a staff of roughly 2500 staff members, while the UNSCEAR and the ICRP are very small organizations with limited budgets and small secretariats. For instance, the ICRP currently has seven staff members, while the UNSCEAR secretariat consist of nine individuals. Furthermore, small budgets and small secretariats cause certain constraints on the secretariats, and staff in both the UNSCEAR and the ICRP report that they must turn down invitations to participate in meetings, due to a lack of travel budgets and time constraints. Moreover, the UNSCEAR is funded by the UN over a biannual budget, while the ICRP has no, or very limited permanent funding. The secretariats must therefore prioritize according to what they consider to be their core role. The ICRP staff, in particular, emphasize that a big part of their job is to make sure that the ICRP has enough money to operate according to the organization's goals.

Considering other types of resources, the data show that all the organizations hold relevant information, knowledge, and expertise, both in their secretariats and through individual experts invited to participate in both expert and task groups. These resources are also fundamental to the organizations' functioning and for their main tasks. However, the IAEA is the only one of the three with explicit political authority, while they all have some degree of epistemic authority, and epistemic authority is particularly evident in the ICRP: 
The ICRP is not part of the UN, like UNSCEAR and the IAEA. They are not beholden to any government. They are pretty much fully independent, and all their funds come from voluntary contributions. ... A second crucial point, though, is that the ICRP take a lot of care into making good recommendations. If they got into a habit of making bad recommendations, the ICRP would disappear. It would become irrelevant. ... The fact that the ICRP still exist, based on voluntary contributions, means somebody thinks they are doing a good job. ... ICRP provide recommendations and they're only recommendations, just suggestions formally, they have no weight whatsoever in terms of legal weight. So, the IAEA set standards and recommendations that have some legal weight. (Interviewee A)

Moreover, interviewees describe how the IAEA benefit from the epistemic authority of the ICRP:

IAEA also has an important reason to collaborate with ICRP. The IAEA GC is very politicised, and committee discussions may also be hampered by political influences. By the famous decision to follow ICRP recommendations as far as possible, IAEA has created a way for itself to evade some of the political flak. (Interviewee 7)

The data suggest that there is little or no tension related to resources in the relationship involving the IAEA. However, there are some tensions between the UNSCEAR and the ICRP related to the epistemic authority, in particular. The data indicate that both offer epistemic authority, a trait that is at the very core of two organizations. Hence, neither of them can afford to jeopardize this authority because it will threaten their very foundations. The radon situation illuminates this tension:

The result of the IAEA-meeting was the development of a joint statement from the UNSCEAR and the ICRP, and the statement did calm the situation down, at least to some degree. However, many felt that the statement could have been even more clear. And actually, it is a joint document, but it's basically just each of them explaining their view. So, in my opinion there is some sort of prestige involved. It's difficult to explain why, but that is my impression. (Interviewee 34)

\section{Moreover:}

There is room to change [the ICRP recommendations] if you have new scientific evidence. But if the science is the same, then the concern, the overriding concern, is loss of credibility with the general public. ... The credibility is the single most valuable resource. (Interviewee 5)

The data thus suggest that tensions between the UNSCEAR and the ICRP, are linked to a fear of losing credibility and thus leading to a reduction or loss of the epistemic authority held. 


\section{Tasks and responsibilities}

The data suggest that there are more blurry lines between the tasks and responsibilities of the UNSCEAR and the ICRP, compared to the lines toward the IAEA, and this causes tensions between the UNSCEAR and the ICRP. In the relationship involving the IAEA, the data suggests that there is a very clear separation of tasks and responsibilities between the UNSCEAR, the ICRP, and the IAEA. Indeed, they all need each other to some degree:

They [the UNSCEAR, the ICRP and the IAEA] could actually not be one without the others. So, if one actor would cease to exist, then the mandate and the goals should be changed. So, for example, if UNSCEAR disappeared, there should be some other organization to make the scientific basis. (Interviewee C)

However, the data suggests that there are instances of overlap, especially between the UNSCEAR and the ICRP, and this overlap may cause tensions:

There's always the potential for a bit of friction because, I mean, on paper, it should be that UNSCEAR reviews the science, ICRP takes the science and produces a system of protection. IAEA is very much about practical applications of that system. ... But of course, there are overlaps between them. And I just mentioned one particular one on radon where, you know, in my opinion the UNSCEAR have exceeded their brief slightly. They've come out with dose coefficients when really, it's ICRPs job. UNSCEAR should just review the science and then work in tandem with ICRP. But ICRP also, to be fair, steps on the toes of UNSCEAR because ICRP decides to do its own reviews of literatures as well. (Interviewee I)

In sum, the empirical findings suggest that the relationship between the UNSCEAR and the ICRP are more prone to tensions and potential conflicts, compared to the relationship involving the IAEA. To account for variation, this article studies the impact of organization type, organization size, and organizational birthmarks, and the following sections discuss these variables in relation to the empirical findings.

\section{Explaining variation}

This paper suggests that organization type, organization size and organization birthmarks may influence cooperation and conflicts between organizations. Considering organization type, the paper makes three propositions. First, the empirical findings support P1, and it is especially evident in the formal relations between the organizations. The data show that the ICRP more actively seek formal relations toward other organizations, compared to the UNSCEAR and the IAEA, and the ICRP also welcome active participation and not just observers. In relation to informal information sharing, the ICRP seem to prioritize the IAEA over the UNSCEAR. Consequently, information tends to flow more easily from the ICRP to the two other organizations, and toward the IAEA in particular, than the other way around, and it may contribute to explain why there are less tensions between the ICRP and the IAEA, compared 
to the relationship between the ICRP and the UNSCEAR. Secondly, the data also support P2. The data show that tensions related to resources are especially evident in the relationship between the UNSCEAR and the ICRP, and not in the relationship involving the IAEA. The data suggests that the UNSCEAR and the ICRP are highly dependent upon the same resources, and their epistemic authority in particular. Hence, they fail to offer distinct resources and the data imply that tensions arise because they need to protect their epistemic authority. Thirdly, P3 is also supported, and the data show that there is some friction between the UNSCEAR and the ICRP because they are more prone to have overlapping roles and responsibilities. In contrast, the relationship involving the IAEA has a much clearer division of labour between the three organizations.

Next, regarding the size of an organization, the data support P4 by showing how both the UNSCEAR and the ICRP, as small organizations, seek cooperation toward the IAEA. However, this pattern is more apparent in the ICRP compared to the UNSCEAR. Combined with organization type, the data thus suggest that the IAEA is indispensable both due to the resources it holds, especially its political authority, and also due to its size. Simultaneously, the data indicate that the ICRP has a double vulnerability related both to organization type and organization size, and combined these traits prompt the ICRP to safeguard cooperation toward the IAEA in particular. Moreover, the data show that interactions between the IAEA, and both the UNSCEAR and the ICRP, are more frequent, compared to interactions between the UNSCEAR and the ICRP, and thus P5 is supported. Consequently, the data imply that the small secretariats of the UNSCEAR and the ICRP makes it more difficult for them to uphold continuous flows of information toward a wide range of actors, and they need to prioritize some organizations over others. The data also indicate that the UNSCEAR and the ICRP, to a greater degree than the IAEA, lean on informal interactions to compensate for the limitations due to the small secretariat:

The secretariat is very small, but the ICRP members are everywhere, and that is a nice advantage of being a volunteer organization. So, the ICRP has these connections that are both official and unofficial, and they are very strong and very useful. (Interviewee A)

This, however, makes the UNSCEAR and the ICRP more vulnerable to changes in personnel, both in the staff and in the experts affiliated with the organizations.

Regarding organizational birthmarks, P6 is also supported by the empirical findings. Hence, the data suggest that birthmarks is important to understand both the relationship involving the IAEA and the relationship and tensions between the UNSCEAR and the ICRP. Historically, the oldest of the three organizations is the ICRP which was established in 1928. It was created to address the growing concerns about the effects of ionizing radiation being observed in the medical community. At its inception, the ICRP consisted of only a handful of people, and they only met one day every third year. Moreover, the ICRP did not have funds to cover travelling costs or payment to individuals doing administrative tasks. Hence, the most important resource for the ICRP, was linked to the experts affiliated with the organization. Consequently, the ICRP carry two important birthmarks which influences its relationships toward other organizations: It had a somewhat broad and nebulous 
mandate, not restricted to the development of recommendations, and the ICRP was a small NGO both regarding funding and staff. The UNSCEAR was established by the General Assembly of the United Nations in 1955 to be a scientific committee assessing and reporting levels and effects of ionizing radiation. Initially, it had 15 member states, represented by senior scientists. It also had a small secretariat, and it was funded over the UN-budget. The IAEA was created in 1957 with the rather broad objective to accelerate and enlarge the contribution of atomic energy to peaceful purposes. From the beginning, it was also a big IGO with 59 member states, and it had security regarding funding and staff. Moreover, the IAEA was fuelled with some degree of political authority. Considering the inter-organizational relationships between the UNSCEAR, the ICRP and the IAEA today, compared to how they were at their inception, the data suggests that birthmarks related to resources, initial tasks, and key individuals, are particularly important to understand both the relationship involving the IAEA and the relationship between the UNSCEAR and the ICRP.

First, the data suggest that a lack of resources like funding, staff, and political authority in the UNSCEAR and the ICRP, compared to the IAEA, influenced the relationship from the very beginning and that these traits remain today. To illustrate, the first chairman of the ICRP, Rolf Sievert, felt the need to both secure cooperation toward bigger and better-equipped organizations, and also to eliminate the possible threat of other organizations, like the UNSCEAR, entering the domain of the ICRP:

Sievert would later word his concern about ICRP's future in a letter: 'Frankly speaking, I always feel concerned when we speak of the world-wide recognition of ICRP ... If we continue on the present scale of our work, I am sure that we will soon lose our reputation ... Do you really think that ICRP with its limitation in specialists and means can take the responsibility of establishing [dose limits] affecting the entire atomic energy work? I am convinced that this will, within a few years, be impossible if we are not closely linked to a powerful safety organization working on a very broad basis.' So, Sievert was worried that, as a consequence of a lack of resources, ICRP would not be able to live up to the requirements that would be set by the Commission, and that other international partners would take over. In another letter, he wrote: 'I worry very much about how our Commissions will be able to compete with an organization set up by the UN including many of the specialists in our Commissions and Committees and having the advantage of being able to get substantial support from the UN'. (Bo Lindell, in 'The Labours of Hercules')

An important aim for Sievert was thus to establish a formal relationship toward the IAEA, which was in place in 1959. Moreover, he had concrete plans to expand the ICRP into a single international authority, also taking on the role of the UNSCEAR. However, he did not succeed in this effort and in 1958 the UN's General Assembly guaranteed the continued activity of the UNSCEAR. Second, from the beginning the ICRP needed to establish a scientific foundation for its work, simply because it did not exist at the time. Hence, the ICRP was not set up solely to make recommendation, and the initial role and responsibility of the ICRP was challenged when the UNSCEAR was created: 
It is important to remember that ICRP was like a grandfather when UNSCEAR was established decades after the creation of ICRP. From the beginning, ICRP needed to be an organization doing research and it worked with the scientific foundation. Now, it is often described as if the work and conclusions of the ICRP, primarily is based on what the UNSCEAR is saying. It may be true to some degree, however, it is not the whole truth. And there are surely different opinions between different people regarding what is my role and what is yours. (Interviewee 7).

Consequently, the data suggest that the relationship between the IAEA and the ICRP, in particular, was based on ICRPs perceived need to be affiliated with a bigger and more powerful organization. Furthermore, the same need seems to persist today, and thus the relationship involving the IAEA remain stable and with few tensions. However, the data indicate that potential conflicts related to resources and domains, were present in the relationship between the UNSCEAR and the ICRP from the beginning, but such possible conflicts did not surface:

I received a letter from Francesco Sella, then Secretary of UNSCEAR. Francesco was a good friend and so I was rather surprised at the tone of his letter, in which he protested about ICRP entering a field that he felt was properly the purview of UNSCEAR. I don't remember exactly how we dealt with the matter, but it all passed off quietly, and we heard no more on the subject from Francesco. Indeed, from then on ICRP had excellent relations with UNSCEAR. (David Sowby in "Some recollections of UNSCEAR")

Today, however, tension between the UNSCEAR and the ICRP seem to be more apparent, and the data indicate that it is linked to birthmarks and the role of key individuals. Scholars argue that relationships between organizations often are initiated, nurtured, and executed at the individual level (Koops, 2017: 201), and key individuals, often leaders, impact flows of information, trust and conflict resolution between organizations (Faerman et al., 2001; Kille \& Hendrickson, 2010; Kroeger, 2012; Reinalda \& Kille, 2017: 228; Schotter et al., 2017; Zaheer et al., 1998). In the initial stages of the relationships between the UNSCEAR and the ICRP, some of the most influential people in these organizations knew each other personally, and many had affiliations toward both organizations. The data thus suggests that this overlap was crucial for the inter-organizational cooperation which was developed:

Indeed, what made UNSCEAR function and prosper from its earliest days were its people: their remarkable competence, friendliness, and willingness to work. ... It [the UNSCEAR] would go on to deepen and widen its work and, together with the professionally senior and already greatly respected ICRP - indeed, often with the same people-would become and remain a small corner of world governance. (Ray Appleyard in "The birth of UNSCEAR — the midwife's tale")

Important examples of key individuals which facilitated cooperation between the UNSCEAR and the ICRP from the early years are Rolf Sievert, David Sowby, 
and Bo Lindell. Furthermore, the data suggest that information sharing and trust between the UNSCEAR and the ICRP to a high degree was built upon people with strong ties to both organizations, and these people knew each other personally. A prominent example is the relationship between Bo Lindell and Daniel Beninson, and after Beninsons death, Bo Lindell wrote:

Dan was my best friend. The friendship began in 1956, when I was called to Rolf Sievert's office to meet a visitor from the secretariat of the new scientific committee of the United Nations, UNSCEAR. ... We found that we had the same views on radiation protection and the basic protection policy, and for that matter on almost everything. We cooperated to the extent that we were somewhat maliciously referred to as the 'Beninson-Lindell mafia'. During the forty-seven years of our friendship, we never once disagreed on any issue. We reached positions that made it possible for us to influence the international development of radiation protection and the view on radiation risks in ICRP and UNSCEAR. (Bo Lindell in "Tribute to Dan Beninson")

Furthermore, the data suggests that these organizations still are dependent upon such people, however, there are fewer people facilitating information sharing and trust now, compared to earlier:

Human interaction is essential, and the number of people is not infinite. I know people who have been both the chairman of ICRP, a representative in the UNSCEAR, and also a representative in the CSS. And this may be the reason why they have been so connected.... So, these relationships are essential, and I'm actually very worried now because these connections are not as good as they used to be. After so many years in this line of work, I smell problems, and this is a potential problem, and with the radon it didn't work well. (Interviewee B)

And:

Back in the days it was basically a handful of people. Now, the older generation is retiring and there are not many around who still remember, who has this historical memory, which is essential in my opinion. ... So, overlap of people is decreasing, and it may impact the level of trust. (Interviewee 5)

Consequently, the data imply that birthmarks linked to resources, tasks, responsibilities, as well as key individuals, are vital to understanding the two different inter-organizational relationships discussed in this paper. Cooperation between the UNSCEAR, the ICRP and the IAEA seem to have been rather stable from the beginning, however, the initial cooperation between the UNSCEAR and the ICRP has developed some tensions. To understand these tensions, the data suggests that cooperation originally was based on close relationships between key individuals, often affiliated with both the UNSCEAR and the ICRP. Furthermore, the data imply that other potential conflicts between these two organizations, related to resources and domains, were held in check by these strong 
inter-personal relationships because they facilitated information sharing and trust. In recent years, however, this has changed, and the data indicate that current tensions between the UNSCEAR and the ICRP have emerged in part because the organizations lack these strong inter-personal relationships which the cooperation was, and still is, dependent upon.

\section{Conclusion}

This paper asks what shape cooperation and conflict between organizations at the global level, and why conflicts arise between organizations with a longstanding history of cooperation. The paper suggests that inter-organizational cooperation and conflict are based on flows of information, trust, resource dependencies and how responsibilities and roles are divided between organizations operating in the same issue area. The data also indicate that organization type, organization size and organization birthmarks, are important to understand patterns of cooperation and conflicts. The paper provides two main insights. First, both organization type and size are important to understand inter-organizational relationships. However, by combining these two characteristics a clear pattern emerges: Big IGOs, which hold political authority, are more autonomous and less vulnerable, compared to small NGOs. It is, therefore, less likely that conflicts will emerge between such organizations because small NGOs will actively adapt to big IGOs in order to uphold cooperation and to remain relevant. However, tensions may develop more easily between small IGOs and small NGOs operating within the same issue area, when they are dependent on overlapping resources. Second, and more intriguingly, the data indicate that organizational birthmarks are important to understand cooperation and conflict by providing a new and deeper understanding of why tensions are triggered in relationships with a longstanding history of cooperation. The data suggest that potential conflicts between organizations may be held in check as long as important functions related to the birthmarks remain relatively stable. However, when changes occur, the organizations fail to adapt due to the birthmarks they carry, and it may trigger tensions which have been a latent part of the inter-organizational relationship from the beginning.

Based on this study, three main avenues for future research are envisaged. First, most of the literature on inter-organizational relations emanate from business administration, and few entries refer to political organizations (Jönsson, 2017: 61). There is thus a need to study more vigorously inter-organizational relations between political organizations situated at the global level. Secondly, the past century has seen a sheer growth in different types of IOs and these IOs address an increasing range of global challenges. To understand the functioning of such organizations, scholars highlight the need to extend and reinvent the analytical toolbox. Future research should thus utilize organization theory to gain new insights and knowledge about IOs, and to further bridge the gap between IO studies and organization theory. Furthermore, IOs and other global actors are part of transnational spaces where activities span different levels. Hence, scholars need to study how different organizations, situated at different levels, work 
together to influence laws, regulations, and policy at the regional and national level.

Acknowledgements The author acknowledges insightful comments and suggestions from participants at the Phd-BBL in April 2021, and also comments from other colleagues at the department of political science and management. Most of all, the author expresses deep gratitude for the invaluable contributions from the interviewees.

Funding Open access funding provided by University of Agder.

\section{Declarations}

Conflict of interest The author declares no conflict of interest.

Open Access This article is licensed under a Creative Commons Attribution 4.0 International License, which permits use, sharing, adaptation, distribution and reproduction in any medium or format, as long as you give appropriate credit to the original author(s) and the source, provide a link to the Creative Commons licence, and indicate if changes were made. The images or other third party material in this article are included in the article's Creative Commons licence, unless indicated otherwise in a credit line to the material. If material is not included in the article's Creative Commons licence and your intended use is not permitted by statutory regulation or exceeds the permitted use, you will need to obtain permission directly from the copyright holder. To view a copy of this licence, visit http://creativecommons.org/licen ses/by/4.0/.

\section{References}

Ahrne, G., \& Brunsson, N. (2005). Organizations and meta-organizations. Scandinavian Journal of Management, 21(4), 429-449. https://doi.org/10.1016/j.scaman.2005.09.005

Alexander, E. (1995). How organizations act together: Interorganizational coordination in theory and practice. Gordon and Breach.

Bachmann, R., Knights, D., \& Sydow, J. (2001). Trust and control in organizational relations. Organization Studies., 22(2), v-viii. https://doi.org/10.1177/0170840601222001.

Barnett, M. N., \& Finnemore, M. (2004). Rules for the world: International organizations in global politics. Cornell University Press.

Bauer, M. W., \& Ege, J. (2016). Bureaucratic autonomy of international organizations' secretariats. Journal of European Public Policy, 23(7), 1019-1037.

Biermann, R., \& Harsch, M. (2017). Resource dependence theory. In R. Biermann, \& J. Koops (Eds.), Palgrave handbook of inter-organizational relations in world politics. Palgrave Macmillan.

Biermann, R., \& Koops, J. (2017). Studying relations among international organizations in world politics: Core concepts and challenges. In R. Biermann, \& J. Koops (Eds.), Palgrave handbook of interorganizational relations in world politics. Palgrave Macmillan.

Boswell, C. (2017). The role of expert knowledge in international organizations. In A. Littoz-Monnet (Ed.), The politics of expertise in international organizations. Routledge.

Brugger, P., Hasenclever, A., \& Kasten, L. (2017). Trust among international organizations. In R. Biermann, \& J. Koops (Eds.), Palgrave handbook of inter-organizational relations in world politics. Palgrave Macmillan.

Buchana, Y., Garbutt, M., \& Seymour, L. F. (2018). Identifying micro-level generative mechanisms of ICT-enabled performance improvement in resource-constrained healthcare organisations: A critical realist perspective. Electronic Journal of Information Systems in Developing Countries, https://doi. org/10.1002/isd2.12057.

Charnovitz, S. (2011). Accountability of public and private international organizations. In B. Reinalda (Ed.), The Ashgate research companion to non-state actors (pp. 333-346). Ashgate. 
Costa, A. C., Fulmer, C., \& Anderson, N. (2018). Trust in work teams: An integrative review, multilevel model, and future directions. Journal of Organizational Behavior, 39(2), 169-184.

Cropper, S., Ebers, M., Huxham, C., \& Smith, P. R. (2008). Introducing inter-organizational relations. In C. Steve, E. Mark, H. Chris \& S. Ring (Eds.), The oxford handbook of inter-organizational relations. Oxford: Oxford University Press.

Egeberg, M., \& Trondal, J. (2018). An organizational approach to public governance: Understanding and design. Oxford University Press.

Faerman, S., McCaffrey, D., \& Van Slyke, D. (2001). Understanding interorganizational cooperation: Public-private collaboration in regulating financial market innovation. Organization Science, 12(3), 372-388. https://doi.org/10.1287/orsc.12.3.372.10099

Finnemore, M. (2014). Dynamics of global governance: Building on what we know. International Studies Quarterly, 58(1), 221-224.

Franke, U. (2017). Inter-organizational relations: Five theoretical approaches. In Oxford research encyclopedia of international studies. Oxford University Press.

Fulmer, C. A., \& Gelfand, M. J. (2012). At what level (and in whom) we trust: Trust across multiple organizational levels. Journal of Management, 38(4), 1167-1230. https://doi.org/10.1177/01492 06312439327

Gornitzka, Å., \& Sverdrup, U. (2011). Access of experts: Information and EU decision-making. West European Politics., 34(1), 48-70.

Harrington, B. (2017). Studying elite professionals in transnational settings. In L. Seabrooke, \& L. F. Henriksen (Eds.), Professional networks in transnational governance. Cambridge University Press.

Hillman, A. J., Withers, M. C., \& Collins, B. J. (2009). Resource dependence theory: A review. Journal of Management, 35(6), 1404-1427. https://doi.org/10.1177/0149206309343469

Jönsson, C. (2017). IR paradigms and inter-organizational theory: Situating the research program within the discipline. In R. Biermann, \& J. Koops (Eds.), Palgrave handbook of inter-organizational relations in world politics. Palgrave Macmillan.

Karns, M., Mingst, K., \& Stiles, K. (2015). International organizations: The politics and processes of global governance (3rd ed.). Lynne Rienner.

Kille, K., \& Hendrickson, R. (2010). Secretary-general leadership across the United Nations and NATO: Kofi Annan, Javier Solana, and operation allied force. Global Governance, 16(4), 505-523.

Koops, J. (2017). Inter-organizationalism in international relations. A mulitilevel framework for analysis. In R. Biermann, \& J. Koops (Eds.), Palgrave handbook of inter-organizational relations in world politics. Palgrave Macmillan.

Krick, E., \& Holst, C. (2020). The socio-political ties of expert bodies: How to reconcile the independence requirements of reliable expertise and the responsiveness requirement of democratic governance. In E. Krick, \& C. Holst (Eds.), Experts and democratic legitimacy: Tracing the social ties of expert bodies in Europe. Routledge.

Kroeger, F. (2012). Trusting organizations: The institutionalization of trust in interorganizational relationships. Organization, 19(6), 743-763. https://doi.org/10.1177/1350508411420900.

Lægreid, P. (2020). Public administration research in Norway: An organisational and institutional approach to political organisations. In G. Bouckaert \& W. Jann (Eds.), European perspectives for public administration (pp. 421-438). Leuven University Press.

Laimer, C. G. (2015). Determinants of interorganizational relationships in science and technology parks: Theoretical and empirical evidence. Gestão \& Regionalidade. https://doi.org/10.13037/gr.vol31n91. 2836

Legrand, T. (2019). Sovereignty renewed. Transgovernmental policy networks and the global-local dilemma. In D. Stone, \& K. Moloney (Eds.), The Oxford handbook of global policy and transnational administration. Oxford University Press.

Lipson, M. (2017). Organization theory and cooperation and conflict among international organizations. In R. Biermann, \& J. Koops (Eds.), Palgrave handbook of inter-organizational relations in world politics. Palgrave Macmillan.

Marquis, C., \& Tilcsik, A. (2013). Imprinting: Toward a multilevel theory. Annals, 7, 195-245. https:// doi.org/10.5465/19416520.2013.766076

Mikecz, R. (2012). Interviewing elites: Addressing methodological issues. Qualitative Inquiry, 18(6), 482-493. https://doi.org/10.1177/1077800412442818

Oliver, C. (1990). Determinants of interorganizational relationships: Integration and future directions. The Academy of Management Review, 15(2), 241-265. 
Olsen, J. P. (2018a). The Bergen approach to public administration and political organization. Norsk Statsvitenskapelig Tidsskrift, 34(4), 188-206.

Olsen, J. P. (2018b). Democratic accountability and the changing European political order. European Law Journal, 24, 77-98. https://doi.org/10.1111/eulj.12261

Paliszkiewicz, J. (2011). Inter-organizational trust: Conceptualization and measurement. International Journal of Performance Measurement, 1, 15-28.

Petintseva, O., Faria, R., \& Eski, Y. (2019). Interviewing elites, experts and the powerful in criminology. Palgrave Macmillan. https://doi.org/10.1007/978-3-030-33000-2

Reinalda, B., \& Kille, K. (2017). The evolvement of international secretariats, executive heads and leadership in inter-organizational relations. In R. Biermann, \& J. Koops (Eds.), Palgrave handbook of inter-organizational relations in world politics. Palgrave Macmillan.

Ruggie, J. G. (1998). Constructing the world polity (The new international relations series). Routledge.

Schneiker, A. (2017). NGO-NGO relations. In R. Biermann, \& J. Koops (Eds.), Palgrave handbook of inter-organizational relations in world politics. Palgrave Macmillan.

Schotter, A. P. J., Mudambi, R., Doz, Y. L., \& Gaur, A. (2017). Boundary spanning in global organizations. Journal of Management Studies, 54(4), 403-421.

Scott, W. R. (2008). Institutions and organizations: Ideas and interests (3rd ed.). Sage Publications.

Smith, C., \& Elger, T. (2014). Critical realism and interviewing subjects. In P. K. Edwards, J. O’Mahoney, \& S. Vincent (Eds.), Studying organizations using critical realism. Oxford: Oxford University Press.

Steffek, J. (2013). Explaining cooperation between IGOs and NGOs-Push factors, pull factors, and the policy cycle. Review of International Studies, 39(4), 993-1013. https://doi.org/10.1017/S026021051 2000393

Stinchcombe, A. L. (1965). Social structure and organizations. In J. G. March (Ed.), Handbook of organizations (pp. 142-193). Rand McNally \& Co.

Stone, D., \& Ladi, S. (2015). Global public policy and transnational administration. Public Administration, 93(4), 839-855. https://doi.org/10.1111/padm.12207

Tallberg, J., Sommerer, T., \& Squatrito, T. (2013). The opening up of international organizations: Transnational access in global governance. Cambridge University Press.

Van de Ven, A. (1976). On the nature, formation, and maintenance of relations among organizations. The Academy of Management Review, 1(4), 24-36.

Weiss, T. G., \& Wilkinson, R. (2018). From international organization to global governance. In T. G. Weiss, \& R. Wilkinson (Eds.), International organization and global governance (2nd ed.). Routledge.

Yang, T. M., \& Maxwell, T. A. (2011). Information-sharing in public organizations: A literature review of interpersonal, intra-organizational and inter-organizational success factors. Government Information Quarterly, 28(2), 164-175. https://doi.org/10.1016/j.giq.2010.06.008

Zaheer, A., McEvily, B., \& Perrone, V. (1998). Does trust matter? Exploring the effects of interorganizational and interpersonal trust on performance. Organization Science, 9(2), 141-159. https://doi.org/ 10.1287/orsc.9.2.141

Zürn, M. (2017). From constitutional rule to loosely coupled spheres of liquid authority: A reflexive approach. International Theory, 9(2), 261-285. https://doi.org/10.1017/S1752971916000270

Publisher's note Springer Nature remains neutral with regard to jurisdictional claims in published maps and institutional affiliations. 